\title{
Awakening the sleeping giant: methods for reactivating the inactive $X$ chromosome as clinical treatment for $\mathrm{X}$-linked disorders
}

\author{
Andrea Cerase \\ European Molecular Biology Laboratory, Monterotondo 00015, Italy. \\ Correspondence to: Dr. Andrea Cerase, European Molecular Biology Laboratory, Via Ramarini 32, Monterotondo 00015, Italy. \\ E-mail: andrea.cerase@embl.it
}

How to cite this article: Cerase A. Awakening the sleeping giant: methods for reactivating the inactive $\mathrm{X}$ chromosome as clinical treatment for X-linked disorders. J Trans/ Genet Genom 2018;2:3.https://doi.org/10.20517/jtgg.2018.02

Received: 13 Jan 2018 First Decision: 18 Jan 2018 Revised: 21 Jan 2018 Accepted: 22 Jan 2018 Published: 1 Mar 2018

Science Editor: Jian-Min Chen Copy Editor: Jun-Yao Li Production Editor: Huan-Liang Wu

During evolution, the mammalian X chromosome acquired brain-related genes. Mutations of X-linked genes account for up to $30 \%$ of intellectual disabilities, $20 \%$ of which are linked to autism spectrum disorders ${ }^{[1,2]}$. Epimutations on the $\mathrm{X}$ chromosome have also been associated with a number of mental health conditions (e.g. depression, bipolar disorder and schizophrenia) ${ }^{[3-6]}$. Thanks to X chromosome inactivation (XCI), a mechanism which reversibly silences one of the two X chromosomes in females, female mammals are a somatic mosaic of two populations of cells, expressing either the paternal or the maternal X chromosome, usually in a 50-50 ratio $^{[7-9]}$. This aspect of female biology is particularly relevant for X-linked dominant disorders. Indeed, while males die at birth or have very severe phenotypes from X-linked mutations, heterozygous female mammals tolerate them, due to the presence of the wild type $(W T)$ gene on the other X chromosome ${ }^{[10]}$. Therefore, in females, it is in principle possible to re-activate the WT XCI-silenced copy of the gene in order to alleviate or rescue any given disease phenotype. This is critical for a variety of genetic pathologies, ranging from poorly characterized genetic diseases such as CDKL5 syndrome to more frequent and better-described diseases, such as Rett syndrome.

In this special issue, Cantone ${ }^{[11]}$ describes the reversal of XCI during development and reprogramming by expression of pluripotency factors, cell fusion or somatic cell nuclear transfer. Cantone ${ }^{[1]}$ also compares and contrasts human and mouse systems, emphasising significant differences between them. Przanowski et al. ${ }^{[12]}$ discuss pharmacological and genetic ways to reactivate the inactive $\mathrm{X}$ chromosome (Xi). They summarise the efforts that have been made to date to achieve Xi reactivation using these approaches alone or in combination. The authors also compare various experimental cellular systems, highlighting the benefits and limitations of

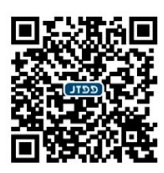


these reporter systems. Reviews from both teams are highly complementary and provide the reader with an accurate, comprehensive picture of the progress made so far in this field.

Partial reactivation of the inactive $\mathrm{X}$ chromosome for therapeutic approaches has so far proven hard to achieve and control. Nevertheless, it offers a new and exciting perspective for curing X-linked disorders. Most importantly, I believe that the knowledge gained by studying the reversal of the Xi goes well beyond X inactivation. Similar strategies could be used for treating a broad range of common illnesses, such as mental health disorders linked to epigenetic gene-silencing, and some forms of cancer.

\section{DECLARATIONS}

\section{Authors' contributions}

Cerase A contributed solely to this editorial.

\section{Financial support and sponsorship}

None.

\section{Conflicts of interest}

There are no conflicts of interest.

\section{Patient consent}

Not applicable.

\section{Ethics approval}

Not applicable.

\section{Copyright}

(c) The Author(s) 2018.

\section{REFERENCES}

1. Sahin M, Sur M. Genes, circuits, and precision therapies for autism and related neurodevelopmental disorders. Science 2015;350:aab3897.

2. Vissers LE, Gilissen C, Veltman JA. Genetic studies in intellectual disability and related disorders. Nat Rev Genet 2016;17:9-18.

3. Akbarian S, Nestler EJ. Epigenetic mechanisms in psychiatry. Neuropsychopharmacology 2013;38:1-2.

4. Chase KA, Rosen C, Rubin LH, Feiner B, Bodapati AS, Gin H, Hu E, Sharma RP. Evidence of a sex-dependent restrictive epigenome in schizophrenia. J Psychiatr Res 2015;65:87-94.

5. Houtepen LC, van Bergen AH, Vinkers $\mathrm{CH}$, Boks MP. DNA methylation signatures of mood stabilizers and antipsychotics in bipolar disorder. Epigenomics 2016;8:197-208.

6. Sun H, Kennedy PJ, Nestler EJ. Epigenetics of the depressed brain: role of histone acetylation and methylation. Neuropsychopharmacology 2013;38:124-37.

7. Cerase A, Pintacuda G, Tattermusch A, Avner P. Xist localization and function: new insights from multiple levels. Genome Biol 2015;16:166.

8. Pintacuda G, Young AN, Cerase A. Function by structure: spotlights on Xist long non-coding RNA. Front Mol Biosci 2017;4:90.

9. Pinter SF. A tale of two cities: how Xist and its partners localize to and silence the bicompartmental X. Semin Cell Dev Biol 2016;56:1934.

10. Franco B, Ballabio A. X-inactivation and human disease: X-linked dominant male-lethal disorders. Curr Opin Genet Dev 2006;16:2549.

11. Cantone I. Reversal of X chromosome inactivation: lessons from pluripotent reprogramming of mouse and human somatic cells. $J$ Transl Genet Genom 2017;1:1-14.

12. Przanowski P, Waśko U, Bhatnagar S. Novel molecular players of $\mathrm{X}$ chromosome inactivation: new technologies and new insights. $J$ Transl Genet Genom 2018;2:2. 